\title{
Características produtivas e qualitativas de mini abóbora em dois sistemas de cultivo
}

\author{
Márcia M Echer; Graciela M Dalastra; Tiago L Hachmann; Mayara S Fiametti; Vandeir F Guimarães; \\ Paulo SR Oliveira \\ UNIOESTE,C. Postal 91, 85960-000 Marechal Cândido Rondon-PR; mmecher@bol.com.br; gradalastra@hotmail.com; \\ tiagohach@gmail.com; mayarafiametti@hotmail.com; vandeirfg@yahoo.com.br; rabello.oliveira@hotmail.com
}

\section{RESUMO}

O objetivo deste trabalho foi avaliar a influência das plantas de cobertura sobre dois sistemas de produção (plantio convencional e plantio direto) nas características produtivas, físicas e químicas da abóbora 'Mini-Jack'. O experimento foi conduzido na Universidade Estadual do Oeste do Paraná, em Marechal Cândido Rondon-PR. O delineamento experimental adotado foi de blocos ao acaso em esquema fatorial $5 \times 2$, com quatro repetições. Os tratamentos constaram de cinco espécies de plantas de coberturas de solo (Lolium multiflorum, Vicia sativa, Avena strigosa, Raphanus sativus e uma mistura das espécies) e dois sistemas de manejo de solo (plantio direto na palha e preparo convencional). Após a condução da cultura, os frutos foram avaliados quanto aos diâmetros transversal e longitudinal, espessura da polpa, número de frutos por planta, número de frutos total, massa média de um fruto e massa média por planta. Foram determinados $\mathrm{pH}$, acidez titulável e teor de sólidos solúveis dos frutos, além da produtividade. $\mathrm{O}$ azevém foi a espécie que produziu maior quantidade de massa seca. A ervilhaca aumenta a produtividade, enquanto que o nabo proporciona aumento da espessura e do teor de sólidos solúveis da abóbora 'Mini-Jack'. O sistema de plantio direto utilizado não afetou a maioria das características agronômicas da abóbora 'Mini-Jack'. Sendo assim, este sistema pode ser adotado para essa cultura.

Palavras-chave: Curcubita pepo, coberturas de solo, sistema de plantio direto, sistema de plantio convencional.

\begin{abstract}
Productivity and quality characteristics of mini pumpkin in two cropping systems

The aim of this study was to evaluate the influence of cover crops on two production systems (conventional tillage and notillage), concerning yield, besides the physical and chemical characteristics of 'Mini-Jack' pumpkin. The experiment was carried out at the Universidade Estadual do Oeste do Paraná, in Marechal Cândido Rondon, Paraná state, Brazil. The experimental design was randomized blocks in $5 \times 2$ factorial design with four replications. The treatments consisted of five types of cover crops (Lolium multiflorum, Vicia sativa, Avena strigosa, Raphanus sativus and a mixture of species) and two systems of soil management (under no-tillage system and conventional tillage system). After harvest, fruits were evaluated for transversal and longitudinal diameters, pulp thickness, number of fruits per plant, total number of fruits, average weight of a fruit and average mass per plant. We determined $\mathrm{pH}$, titratable acidity and soluble solids of the fruit, as well as productivity. Italian ryegrass produced the highest amount of dry mass. The common vetch increased productivity, whereas the turnip increased thickness and soluble solids of 'Mini-Jack' pumpkin. The no-tillage system did not affect the majority of the agronomic characteristics of 'Mini-Jack' pumpkin, so this system can be adopted for this crop.
\end{abstract}

Keywords: Curcubita pepo, cover crops, no-tillage system, conventional tillage system.

(Recebido para publicação em 20 de junho de 2013; aceito em 12 de junho de 2014) (Received on June 20, 2013; accepted on June 12, 2014)

\begin{abstract}
A produção de hortaliças tem como característica marcante seu caráter intensivo, ou seja, explora de maneira excessiva o solo, mão de obra e insumos. Nesse tipo de cultivo a maioria das plantas apresenta ciclo rápido, deixando o solo descoberto, sobretudo durante o preparo, plantio e início do desenvolvimento da cultura. É uma atividade que degrada intensamente os solos, devido ao uso demasiado de arações e gradagens para o preparo da
\end{abstract}

área a ser cultivada. De acordo com Nascimento Junior et al. (2005) essas operações potencializam a perda de solo, água e nutrientes por erosão, além de promoverem uma maior compactação do solo, devido principalmente à baixa quantidade de matéria orgânica desse solo e intensa movimentação de pessoas e máquinas. Alternativamente ao sistema de plantio convencional tem-se desenvolvido o sistema de plantio direto de hortaliças (SPDH).
O SPDH objetiva "construir um caminho para o desenvolvimento sustentável" (EPAGRI, 2004). Trata-se de um conjunto de ações que visam evitar o revolvimento do solo e que utiliza técnicas como plantas de cobertura e rotação de culturas (Ribeiro et al., 2001). Essas práticas proporcionam benefícios, como maior infiltração de água, redução na erosão e na amplitude térmica, redução na infestação de plantas espontâneas, melhoria na estrutura do solo, além de 
promover a reciclagem de nutrientes. A principal causa desses benefícios é resultado da maior concentração de matéria orgânica, que ocorre em solos onde o plantio direto é praticado (Derpsch \& Calegari, 1992; Melo et al., 2010).

A partir da década de 90 foram desenvolvidos experimentos que demonstram ser possível o cultivo de hortaliças reduzindo o revolvimento do solo, evitando assim a deterioração do mesmo. A estratégia adotada por Abdul-Baki \& Teasdale (1993), citado por Oliveira (2004), foi utilizar leguminosas de inverno como ervilhaca peluda e trevo subterrâneo (Trifolium subterraneum), onde, após terem atingido seu desenvolvimento máximo, as plantas foram cortadas e deixadas sobre o solo, sendo as mudas de tomate transplantadas em pequenas covas abertas sobre essa palhada. Esses autores observaram que a produção foi semelhante à obtida com o preparo convencional do solo, além da menor necessidade de uso de inseticidas e fertilizantes.

Ao avaliar os efeitos do pré-cultivo de crotalária (Crotalaria juncea) sobre o desempenho do repolho em sistema de plantio direto, Oliveira et al. (2003) verificaram maior produtividade e peso médio das cabeças de repolho quando comparado ao plantio convencional. Melo et al. (2010), para a produção de brócolis, não verificaram diferença nos níveis de produtividade para os sistemas plantio direto e convencional. Trabalhando com quatro grupos de alface, em sistema convencional e plantio direto na palha de feijão guandu (Cajanus cajan), Echer et al. (2010) observaram maior produtividade para alfaces cultivadas em plantio direto comparadas com o plantio onde ocorreu o revolvimento e preparo do solo.

O cultivo em um sistema de produção que seja mais econômico do ponto de vista da utilização de insumos e mão-de-obra, associado ao cultivo de hortaliças diferenciadas pode ser uma boa alternativa para aumentar a renda do agricultor. $\mathrm{O}$ preço pago por produtos diferenciados é maior, justamente devido à maior qualidade desses produtos e à sua "exclusividade".

Uma das hortaliças diferenciadas recentemente desenvolvidas são as mini-abóboras, que foram criadas a fim de atender a demanda por frutos de tamanhos menores, para facilitar o transporte e atender o consumo das pequenas famílias. Elas possuem vida de prateleira longa, são de excelente sabor e tamanho ideal para pratos individuais.

No início dos anos 90 o mercado de hortaliças em miniatura registrou evolução muito rápida nos países desenvolvidos da Europa e nos Estados Unidos da América. $\mathrm{O}$ estímulo veio da valorização desses produtos nas cozinhas gourmet e redes fast food. Inicialmente apenas os chefs de restaurantes as usavam em seus pratos, mas a partir de 2000 essas hortaliças diferenciadas passaram a ser encontradas também no varejo e em supermercados. Pesquisadores do CEPEA (Centro de Estudos Avançados em Economia Aplicada) apontam que esses produtos apresentam como diferenciais o menor porte e a maior facilidade de consumo e preparo (CEPEA, 2013). Além disso, proporcionam aspecto moderno aos pratos e muitos são mais saborosos, tornando-se mais atrativos, tanto visualmente quanto pelo paladar.

As pesquisas com hortaliças em sistema de plantio direto são crescentes no Brasil e no mundo, com uma forte tendência de ser adotada pela maioria dos produtores. Porém, são escassas as informações agrotecnológicas sobre os benefícios desta prática e da influência dos diferentes tipos de plantas de cobertura nas características agronômicas da cultura da mini-abóbora em sistema de plantio direto. Desta forma o objetivo do presente trabalho foi avaliar a influência das plantas de cobertura sobre dois sistemas de produção (plantio convencional e plantio direto) na produtividade e nas características físicas e químicas da abóbora 'Mini-Jack'.

\section{MATERIAL E MÉTODOS}

O experimento foi conduzido de junho a dezembro de 2009 em área da Universidade Estadual do Oeste do Paraná, em Marechal Cândido Rondon-PR (243' 'S, 543 ' 'O, altitude $420 \mathrm{~m}$ ). O solo foi classificado como Latossolo Vermelho Eutroférrico de textura argilosa (Embrapa, 2006).
Para a caracterização química do solo foram realizadas coletas em toda a área experimental, na profundidade 0-20 $\mathrm{cm}$, cujos resultados encontrados foram: $\mathrm{pH}\left(\mathrm{CaCl}_{2}\right)=4,85$; matéria orgânica $=$ $17,77 \mathrm{~g} \mathrm{dm}^{-3} ; \mathrm{P}=53,97 \mathrm{mg} \mathrm{dm}^{-3} ; \mathrm{K}=0,76$ $\mathrm{cmol}_{\mathrm{c}} \mathrm{dm}^{-3} ; \mathrm{Ca}^{2+}=4,29 \mathrm{cmol}_{\mathrm{c}} \mathrm{dm}^{-3} ; \mathrm{Mg}^{2+}=$ $1,52 \mathrm{cmol} \mathrm{dm}^{-3} ; \mathrm{Al}^{3+}=0,13 \mathrm{cmol} \mathrm{dm}^{-3}$; $\mathrm{SB}=6,57 ; \mathrm{T}=10,43 \mathrm{cmol} \mathrm{dm}^{-3} ; \mathrm{H}+\mathrm{Al}=$ $3,73 \mathrm{cmol}_{\mathrm{c}} \mathrm{dm}^{-3}$ e V $(\%)=63,53$.

A implantação deste experimento constou de duas etapas, sendo na primeira feita a semeadura e manejo das plantas de cobertura e na segunda o transplante e condução da mini-abóbora. É importante ressaltar que, anteriormente à realização deste experimento, esta área havia sido cultivada com aveia em sucessão com berinjela, tanto em sistema de plantio direto quanto convencional com incorporação da palhada de aveia. Após o cultivo de berinjela, em ambas as áreas, os restos culturais foram retirados do local, para evitar problemas fitossanitários no próximo cultivo. A área destinada ao plantio convencional foi novamente preparada com aração e gradagem e posteriormente realizada a semeadura das plantas de cobertura. Já para o sistema plantio direto, não houve a incorporação da aveia e após o cultivo da berinjela, ocorreu o revolvimento do solo apenas para a abertura dos sulcos para a semeadura das plantas de cobertura.

As plantas de cobertura [azevém (Lolium multiflorum) ervilhaca comum (Vicia sativa), aveia branca (Avena strigosa), nabo forrageiro (Raphanus sativus)] e uma mistura contendo quantidades iguais das espécies estudadas foram semeadas na densidade de 20,30, 55,20 e $30 \mathrm{~kg} \mathrm{ha}^{-1}$, respectivamente, no início do mês de junho de 2009. Essas plantas foram cortadas rente ao solo 117 dias após a semeadura.

Por ocasião do corte foi realizada amostragem e determinada a biomassa, utilizando uma moldura de 50x50 cm, colocada ao acaso em cada parcela, onde foi coletado todo o material vegetal presente dentro da moldura. Essas amostras foram acondicionadas em sacos de papel e em seguida colocadas para secar em estufa de circulação forçada de ar a $65^{\circ} \mathrm{C}$, até atingir massa constante, para determinação da massa seca acumulada 
das plantas de cobertura e dos sistemas de manejo do solo.

A segunda etapa foi a condução da cultura da abóbora sobre a palhada das plantas de cobertura. O delineamento experimental utilizado foi de blocos ao acaso em esquema fatorial $5 \times 2$, com quatro repetições. Os tratamentos foram constituídos de cinco espécies de plantas de cobertura de solo (azevém, ervilhaca, aveia branca, nabo forrageiro e uma mistura de sementes) e dois sistemas de manejo de solo (plantio direto na palhada e preparo convencional com incorporação das plantas de cobertura).

As mudas de abóbora, cultivar Mini-Jack, foram produzidas em bandejas de poliestireno expandido de 72 células contendo substrato comercial. As bandejas foram mantidas em casa de vegetação até o momento do transplante para o campo. A irrigação das mudas foi realizada de acordo com a necessidade. O transplante das mudas ocorreu aos 19 dias após a semeadura. A adubação da cultura foi realizada de acordo com as análises de solo e recomendações de Trani et al. (1997), sendo a adubação de plantio realizada na cova e a de cobertura por fertirrigação, via gotejamento. O controle fitossanitário foi realizado conforme a necessidade da cultura.

As parcelas experimentais foram constituídas de quatro linhas espaçadas de $1 \mathrm{~m}$, e de quatro plantas por linha com espaçamento entre si de $50 \mathrm{~cm}$, totalizando 16 plantas por parcela expe- rimental, sendo avaliados todos os frutos das quatro plantas centrais da parcela.

A colheita dos frutos foi realizada 46 dias após o transplante das mudas. Estes foram levados ao laboratório, onde foram realizadas as avaliações. Inicialmente foi realizada a contagem do número de frutos por planta e por parcela, posteriormente com auxílio de um paquímetro digital os frutos foram avaliados quanto aos diâmetros transversal e longitudinal e espessura de polpa. A massa média de um fruto e a massa média de frutos por planta foi determinada por meio de uma balança de precisão (BEL modelo mark M 333). A partir da massa média da parcela estimou-se a produtividade em $\mathrm{t} \mathrm{ha}^{-1}$.

Foi amostrada a polpa de quatro frutos por parcela, os quais foram cortados em pedaços menores e homogeneizados em liquidificador para determinação de suas características qualitativas. $\mathrm{O}$ potencial hidrogeniônico $(\mathrm{pH})$ foi determinado pela imersão do eletrodo do peagâmetro digital na solução obtida. O teor de sólidos solúveis (SS) foi determinado por meio de um refratômetro digital, utilizando uma gota da solução. A acidez titulável (AT) foi determinada utilizando-se uma alíquota de $5 \mathrm{~mL}$ de solução, à qual foram adicionados $25 \mathrm{~mL}$ de água destilada e 3 gotas de fenolftaleína. Essa solução, depois de homogeneizada, foi titulada com hidróxido de sódio, e anotada a quantidade utilizada para proceder os cálculos, de acordo com a metodologia proposta pelo Instituto Adolfo Lutz (2005).

Após a tabulação, os dados foram submetidos à análise de variância e as médias comparadas pelo teste de Duncan $(\mathrm{p} \leq 0,05)$, utilizando o programa estatístico SAEG (SAEG, 2007).

\section{RESULTADOS E DISCUSSÃO}

A produção de massa seca da parte aérea das plantas de cobertura foi maior para o azevém e para a combinação de espécies do que para o nabo forrageiro, e não diferiram de ervilhaca e aveia (Figura 1A). Tanto o azevém como a mistura de espécies produziram acima de $6 \mathrm{tha}^{-1}$ de massa seca. Segundo Alvarenga et al. (2001), essa quantidade de matéria seca assegura uma boa cobertura do solo, permitindo assim que os resíduos permaneçam sobre o mesmo por um período prolongado, criando assim uma condição adequada para a implantação do sistema de plantio direto.

O sistema de manejo de solo (plantio convencional com incorporação das plantas de cobertura e plantio direto) não interferiu na produção de massa seca das plantas de cobertura (Figura 1B). Esse resultado é contrário ao obtido por Sodré Filho et al. (2004) ao avaliarem a massa seca de aveia-preta, crotalária júncea, feijão-bravo-do-ceará, guandu, mucuna, girassol e milheto, usadas como plantas de cobertura no ambiente de cerrado. Se-

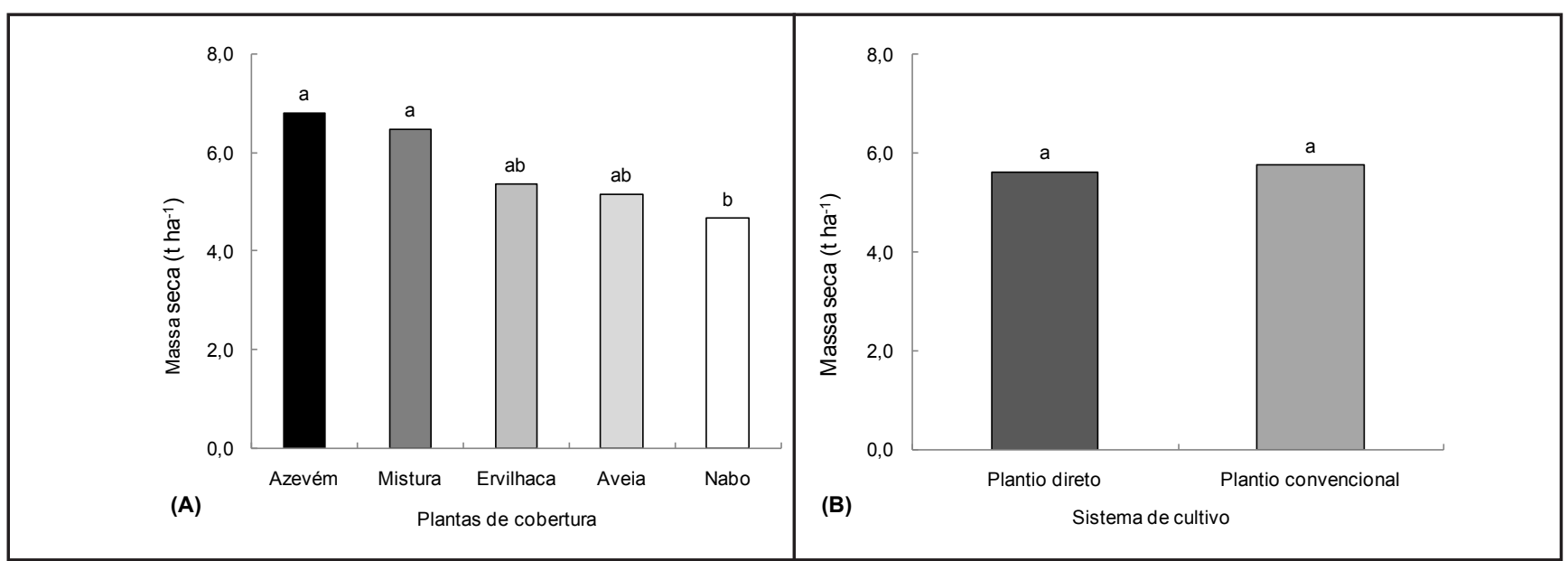

Figura 1. Massa seca da parte aérea de cinco espécies de plantas de cobertura (A) e em dois sistemas de cultivo (B); Médias seguidas da mesma letra não diferem pelo teste de Duncan ( $\mathrm{p}>0,05)$ [dry mass of the aboveground part of five species of cover crops (A) and two cropping systems (B); Means followed by the same letter do not differ by Duncan test ( $\mathrm{p}>0.05)]$. Marechal Cândido Rondon, UNIOESTE, 2009. 
Tabela 1. Potencial hidrogeniônico (pH) e acidez titulável de frutos da abóbora 'Mini-Jack', em função de cinco plantas de cobertura e dois sistemas de plantio ( $\mathrm{pH}$ and titratable acidity of 'Mini-Jack' pumpkin fruits, depending on five cover crops and two cropping systems). Marechal Cândido Rondon, UNIOESTE, 2009.

\begin{tabular}{lccccc}
\hline \multirow{2}{*}{$\begin{array}{l}\text { Plantas de } \\
\text { cobertura }\end{array}$} & \multicolumn{2}{c}{$\mathbf{p H}$} & & \multicolumn{2}{c}{$\begin{array}{c}\text { Acidez titulável } \\
\text { (\% ác. cítrico) }\end{array}$} \\
\cline { 2 - 3 } \cline { 6 - 7 } & $\begin{array}{c}\text { Plantio } \\
\text { Direto }\end{array}$ & $\begin{array}{c}\text { Plantio } \\
\text { Convencional }\end{array}$ & & $\begin{array}{c}\text { Plantio } \\
\text { Direto }\end{array}$ & $\begin{array}{c}\text { Plantio } \\
\text { Convencional }\end{array}$ \\
\hline Azevém & $6,75 \mathrm{Bcd}$ & $6,93 \mathrm{Aa}$ & & $0,80 \mathrm{Ab}$ & $0,72 \mathrm{Ab}$ \\
Ervilhaca & $6,93 \mathrm{Abc}$ & $6,91 \mathrm{Aa}$ & & $0,95 \mathrm{Abc}$ & $0,82 \mathrm{Ab}$ \\
Nabo & $7,01 \mathrm{Aa}$ & $7,03 \mathrm{Aa}$ & & $1,10 \mathrm{Ba}$ & $1,32 \mathrm{Aa}$ \\
Aveia & $6,72 \mathrm{Bd}$ & $6,94 \mathrm{Aa}$ & & $0,35 \mathrm{Bc}$ & $0,67 \mathrm{Ab}$ \\
Mistura & $6,87 \mathrm{Bcd}$ & $7,02 \mathrm{Aa}$ & & $0,97 \mathrm{Abc}$ & $0,80 \mathrm{Ab}$ \\
\hline CV $(\%)$ & & 0,95 & & & 14,75 \\
\hline
\end{tabular}

*Médias seguidas pela mesma letra maiúscula na linha e minúscula na coluna não diferem entre si pelo teste de Duncan a $(\mathrm{p}>0,05)$ (means followed by the same uppercase letter in the line and lowercase in the column, do not differ by the Duncan test, $\mathrm{p}>0.05$ ).

Tabela 2. Diâmetros transversal (DT) e longitudinal (DL) dos frutos, número de frutos por planta (NFP) e produtividade (P) da abóbora 'Mini-Jack', em função de cinco plantas de cobertura [transversal diameter (DT) and longitudinal diameter (DL) of fruits, number of fruits per plant (NFP) and productivity (P) of fruits of 'Mini-Jack' pumpkin, depending on five cover crops]. Marechal Cândido Rondon, UNIOESTE, 2009.

\begin{tabular}{|c|c|c|c|c|}
\hline \multirow{2}{*}{ Plantas de cobertura } & DT & DL & \multirow{2}{*}{ NFP } & \multirow{2}{*}{$P\left(t h^{-1}\right)$} \\
\hline & \multicolumn{2}{|c|}{$(\mathrm{mm})$} & & \\
\hline Azevém & $73,32 \mathrm{a}$ & $45,66 \mathrm{a}$ & $1,88 \mathrm{a}$ & $4,44 \mathrm{ab}$ \\
\hline Ervilhaca & $73,41 \mathrm{a}$ & $43,64 \mathrm{a}$ & $1,63 \mathrm{a}$ & $4,57 \mathrm{a}$ \\
\hline Nabo & $76,18 \mathrm{a}$ & $45,43 \mathrm{a}$ & $1,38 \mathrm{a}$ & $4,15 \mathrm{ab}$ \\
\hline Aveia & $72,60 \mathrm{a}$ & $41,48 \mathrm{a}$ & $1,28 \mathrm{a}$ & $3,81 \mathrm{~b}$ \\
\hline Mistura & $71,56 \mathrm{a}$ & $42,58 \mathrm{a}$ & $1,35 \mathrm{a}$ & $4,36 \mathrm{ab}$ \\
\hline CV $(\%)$ & 7,80 & 10,38 & 17,90 & 14,08 \\
\hline
\end{tabular}

*Médias seguidas da mesma letra na coluna não diferem pelo teste de Duncan $(\mathrm{p}>0,05)$ (means followed by the same letter in the column do not differ by Duncan test, $\mathrm{p}>0.05$ ).

Tabela 3. Número de frutos total (NFT), massa média de frutos por planta (MFP), massa média de um fruto (MF), espessura da polpa (EP) e teor de sólido solúveis (SS) de abóbora 'Mini-Jack', submetidas a cinco diferentes coberturas do solo [number of fruits (NFT), average weight of fruits per plant (MFP), average weight of a fruit (MF), pulp thickness (EP) and soluble solids content (SS) of 'Mini-Jack' pumpkin submitted to five different soil covers). Marechal Cândido Rondon, UNIOESTE, 2009.

\begin{tabular}{|c|c|c|c|c|c|}
\hline \multirow{2}{*}{$\begin{array}{l}\text { Plantas de } \\
\text { cobertura }\end{array}$} & \multirow{2}{*}{ NFT } & MFP & MF & \multirow{2}{*}{$\begin{array}{c}\text { EP } \\
(\mathrm{mm})\end{array}$} & \multirow{2}{*}{$\begin{array}{c}\text { SS } \\
\left({ }^{\circ} \text { Brix }\right)\end{array}$} \\
\hline & & \multicolumn{2}{|c|}{ (g) } & & \\
\hline Azevém & $7,50 \mathrm{a}$ & $1081,90 \mathrm{a}$ & $149,96 \mathrm{a}$ & $11,14 \mathrm{ab}$ & $2,92 \mathrm{~b}$ \\
\hline Ervilhaca & $6,50 \mathrm{a}$ & $968,06 \mathrm{a}$ & $148,19 \mathrm{a}$ & $10,70 \mathrm{ab}$ & $2,88 \mathrm{~b}$ \\
\hline Nabo & $5,50 \mathrm{a}$ & $894,11 \mathrm{a}$ & $162,95 \mathrm{a}$ & $11,52 \mathrm{a}$ & $3,64 \mathrm{a}$ \\
\hline Aveia & $5,13 \mathrm{a}$ & $707,56 \mathrm{a}$ & $134,51 \mathrm{a}$ & $10,08 \mathrm{~b}$ & $3,17 \mathrm{ab}$ \\
\hline Mistura & $5,38 \mathrm{a}$ & $702,35 \mathrm{a}$ & $138,70 \mathrm{a}$ & $10,46 \mathrm{ab}$ & $3,30 \mathrm{ab}$ \\
\hline CV (\%) & 22,38 & 26,25 & 11,24 & 10,25 & 10,77 \\
\hline
\end{tabular}

*Médias seguidas da mesma letra na coluna não diferem pelo teste de Duncan $(p>0,05)$ (means followed by the same letter in the column do not differ by Duncan test $(\mathrm{p}>0.05)$. gundo esses autores, o maior acúmulo de massa seca no sistema de plantio direto ocorre devido ao melhor estabelecimento inicial das plantas, e também devido a um acúmulo sucessivo de resíduos de safras e entressafras. Assim, o sistema de plantio direto pode não ter se sobressaído no presente experimento devido ao curto período em que esse sistema foi implantado na área (aproximadamente 3 anos), para que o sistema esteja consolidado são necessários em torno de cinco anos.

Além disso, deve-se considerar que, no caso do cultivo de hortaliças, os restos culturais favorecem o desenvolvimento de problemas fitossanitários, principalmente doenças, por isso, na maioria das vezes, o que não é comercializado acaba sendo retirado do campo de cultivo para eliminar fontes de inóculo, dificultando e aumentando o tempo para que ocorra o acúmulo de matéria orgânica no solo nos campos de produção.

Houve interação entre sistemas de manejo do solo e plantas de cobertura para $\mathrm{pH}$ e acidez titulável (Tabela 1). Comparando as plantas de cobertura dentro de cada sistema, observa-se que os frutos apresentaram maiores valores de $\mathrm{pH}$ quando foram produzidos na palha de nabo forrageiro em relação às demais plantas de cobertura no sistema plantio direto. Já no sistema plantio convencional não houve diferença entre as espécies. Ao comparar as plantas de cobertura entre os sistemas, observa-se que azevém, aveia branca e a mistura das espécies apresentaram valores superiores para $\mathrm{pH}$ dos frutos no sistema de plantio convencional, quando comparado ao sistema de plantio direto.

Valores de $\mathrm{pH}$ menores ao do presente trabalho foram verificados por Araújo (2011) que, ao trabalhar com o híbrido de abobrinha de moita Aline, obteve valores variando de 6,5 a 6,7 . Esse mesmo autor encontrou valores de acidez titulável dos frutos variando de 0,086 a $0,126 \%$ de ácido cítrico.

Dentro dos sistemas de plantio direto e convencional os frutos de abóbora obtiveram maiores valores de acidez quando foram cultivados sobre a palhada de nabo forrageiro. Ao comparar as plantas de cobertura entre os sistemas, observa-se que o plantio convencional 
Tabela 4. Diâmetros transversal (DT) e longitudinal (DL) dos frutos, espessura de polpa (EP), massa média de um fruto (MF) e produtividade (P) de abóbora 'Mini-Jack', em função de dois sistemas de cultivo [transversal diameter (TD) and longitudinal diameter (DL) of the fruit pulp thickness (EP), average weight of a fruit (MF) and productivity $(\mathrm{P})$ of fruits of 'Mini-Jack' pumpkin, depending on two cropping systems]. Marechal Cândido Rondon, UNIOESTE, 2009.

\begin{tabular}{|c|c|c|c|c|c|}
\hline \multirow{2}{*}{ Sistema de cultivo } & DT & DL & EP & \multirow{2}{*}{$\begin{array}{c}\text { MF } \\
\text { (g) }\end{array}$} & \multirow{2}{*}{$\begin{array}{c}\mathbf{P} \\
\left(t \mathrm{ha}^{-1}\right)\end{array}$} \\
\hline & & $(\mathrm{mm})$ & & & \\
\hline Plantio direto & $71,40 \mathrm{~b}$ & $43,50 \mathrm{a}$ & $10,66 \mathrm{a}$ & $138,73 \mathrm{a}$ & $4,56 \mathrm{a}$ \\
\hline Plantio convencional & $75,43 \mathrm{a}$ & $44,02 \mathrm{a}$ & $10,90 \mathrm{a}$ & $154,97 \mathrm{a}$ & $4,15 \mathrm{a}$ \\
\hline $\mathrm{CV}(\%)$ & 7,80 & 10,38 & 10,25 & 11,24 & 14,08 \\
\hline
\end{tabular}

*Médias seguidas da mesma letra na coluna não diferem pelo teste de Duncan $(p>0,05)$ (means followed by the same letter in the column do not differ by Duncan test, $\mathrm{p}>0.05$ ).

foi superior ao direto quando cultivado sobre a palhada de nabo forrageiro e aveia, não diferindo para as demais plantas de cobertura.

Para os diâmetros transversal e longitudinal dos frutos e número de frutos por planta não foram verificadas diferenças significativas em relação às espécies de plantas de cobertura (Tabela 2). Todos os tratamentos resultaram em frutos com dimensões adequadas, que de acordo com a empresa produtora de sementes desta cultivar devem apresentar diâmetro longitudinal de 4 a 6 $\mathrm{cm}$ e diâmetro transversal em torno de $8 \mathrm{~cm}$. Em relação ao número de frutos por planta, este ficou abaixo do que é recomendado para a cultura ( 5 frutos por planta). Esse reduzido número de frutos por planta pode ter ocorrido devido às altas temperaturas que ocorrem na região, ocasionando o abortamento dos frutos.

A maior produtividade da mini-abóbora foi alcançada quando cultivada na palhada de ervilhaca, não diferindo de azevém, nabo forrageiro e mistura. Essa maior produtividade pode ter ocorrido pela rápida decomposição da massa seca da ervilhaca, disponibilizando rapidamente nitrogênio, e também devido sua baixa relação $\mathrm{C} / \mathrm{N}$, aumentando a disponibilidade dos demais nutrientes para a cultura sucessora.

A boa produtividade que ocorreu para a mistura pode ser decorrência do uso de diferentes espécies como cobertura de solo. Estas proporcionam maior acúmulo de massa seca sobre o solo e os seus sistemas radiculares agem sobre diferentes camadas do solo, proporcio- nando maior tempo de cobertura do mesmo e liberando diferentes compostos secundários, que irão contribuir para o aumento da produtividade (Silveira, 2007; Bittencourt, 2008).

A menor produtividade observada para a cobertura com aveia pode ser explicada em função de que a sua palhada permanece por um período mais prolongado sobre o solo, devido à decomposição mais lenta, consequentemente a liberação de nutrientes ocorre de forma mais gradual. Como o ciclo da mini abóbora foi curto pode não ter ocorrido a liberação total dos nutrientes presentes nessa palhada, gerando prejuízos ao aumento da produtividade da cultura.

Não foram verificadas diferenças significativas para número de frutos total, massa média de frutos por planta e massa média de um fruto (Tabela 3). A maior espessura de polpa foi observada em frutos de plantas cultivadas sobre nabo forrageiro, diferindo significativamente apenas do cultivo sobre aveia. Essa maior espessura pode ser devida à maior disponibilidade de nitrogênio para as plantas de abóbora nesse cultivo, acarretando em maior crescimento da parte comestível do fruto. A relação $\mathrm{C} / \mathrm{N}$ do nabo forrageiro, segundo Giacomini et al. (2003), é de 22,4 a 25,5, colocando o nabo numa posição intermediária entre a aveia e a ervilhaca. Usando esses valores como base, pode-se inferir que, nos tratamentos com ervilhaca e nabo, a mineralização deverá superar a imobilização, resultando em aumento da disponibilidade de $\mathrm{N}$ no solo durante a decomposição dos resíduos culturais (Giacomini et al., 2003).
Os maiores teores de sólidos solúveis foram encontrados nos frutos produzidos sobre a palhada de nabo $\left(3,64^{\circ}\right.$ Brix $)$, o qual diferiu apenas de ervilhaca e azevém (Tabela 3). Esses maiores valores podem ser devidos ao maior aporte de potássio sobre essa cobertura. Em trabalho realizado por Giacomini et al. (2003) o nabo acumulou $99 \mathrm{~kg} \mathrm{ha}^{-1} \mathrm{de} \mathrm{K}$, superando a aveia e a ervilhaca em 23 e $48 \%$, respectivamente. A concentração de $\mathrm{K}$ pelo nabo foi de $23 \mathrm{~kg} \mathrm{ha}^{-1}$ de matéria seca produzida.

Estes valores de sólidos solúveis estão abaixo dos encontrados por Pedrosa et al. (2012) em frutos de moranga híbrida Tetsukabuto, ao testar doses crescentes de nitrogênio, sendo que esses autores obtiveram variação de $4,5^{\circ}$ Brix (dose de $0 \mathrm{~kg} \mathrm{ha}^{-1}$ de $\mathrm{N}$ ) até $8,0^{\circ}$ Brix (dose de $300 \mathrm{~kg} \mathrm{ha}^{-1}$ de N).

Os dados referentes às características produtivas da abóbora, de acordo com sistemas de cultivo, são apresentados na Tabela 4. Não houve diferença estatística entre os sistemas de manejo do solo para as variáveis avaliadas, com exceção do diâmetro transversal, sendo o maior diâmetro de frutos observado no sistema de plantio convencional. Porém não foi observado incremento na produtividade em função desse maior diâmetro. Resultados semelhantes foram observados por Castro et al. (2005) trabalhando com berinjela sob plantio direto e convencional. Contudo, Dalastra et al. (2009), trabalhando com a mesma cultura, observaram maior produtividade em sistema plantio direto. Esses autores observaram também que o plantio direto de berinjela sobre palhada de aveia resultou em frutos com maior diâmetro e comprimento, massa de fruto e produção de frutos por plantas.

Os resultados obtidos no plantio direto sobre palhada e plantio convencional com incorporação das plantas de cobertura, independente da espécie utilizada, foram semelhantes entre si, indicando que a adoção do plantio direto como uma prática conservacionista pode ser realizada sem restrições às características agronômicas para a abóbora 'Mini-Jack'. Silva (2002) e Melo et al. (2010), trabalhando com brócolos, e Castro et al. (2005), trabalhando com berinjela, não encontraram diferenças 
entre os sistemas de plantio direto e convencional, indicando possibilidades concretas de adoção do plantio direto sem prejuízo à produção comercial destas hortaliças.

Incrementos em produtividade no sistema plantio direto foram relatados nas culturas do tomate industrial (Marouelli et al., 2006), tomate de mesa (Epagri, 2004), brássicas (Silva, 2002) e berinjela (Dalastra et al., 2009).

Diante dos resultados apresentados, pode-se concluir que o azevém foi a espécie que produziu maior quantidade de massa seca. A ervilhaca aumenta a produtividade, enquanto que o nabo proporciona aumento da espessura e do teor de sólidos solúveis da abóbora 'Mini-Jack'. O sistema de plantio direto não afetou a maioria das características agronômicas da abóbora 'Mini-Jack'. Sendo assim este sistema pode ser adotado para cultivo dessa espécie.

\section{REFERÊNCIAS}

ALVARENGA RC; CABEZAS WL; CRUZ JC; SANTANA DP. 2001. Plantas para cobertura do solo para sistema de plantio direto. Informe Agropecuário 22: 25-36.

ARAÚJO HS. 2011. Doses de potássio em cobertura na produção e qualidade de frutos de abobrinha-de-moita. Botucatu: UNESP. 92p (Dissertação mestrado).

BITTENCOURT HH. 2008. Culturas de cobertura de inverno na implantação de sistema de plantio direto sem uso de herbicidas. Florianópolis: UFSC. 73p (Dissertação mestrado).

CEPEA, Centro de Estudos Avançados em Economia Aplicada. 2013. ESALQ-USP. Revista HortiFruti Brasil. Disponivel em: http://cepea.esalq.usp.br/hfbrasil/ edicoes/121/full.pdf. Acessado em: 22 de março de 2013.
CASTRO CM; ALMEIDA DL; RIBEIRO RLD; CARVALHO JF. 2005. Plantio direto, adubação verde e suplementação com esterco de aves na produção orgânica de berinjela. Pesquisa Agropecuária Brasileira 40: 495502.

DALASTRA GM; ECHER MM; SCHNEIDER RP; COLOMBARI LF; GISH JK; FIAMETTI MS; GUIMARÃES VF; OLIVEIRA PSR. 2009. Avaliação de características produtivas de seis cultivares de berinjela em sistema de plantio na palha e convencional, na região Oeste do Paraná. In: CONGRESSO BRASILEIRO DE OLERICULTURA, 27. Resumos... Águas de Lindóia: SOB (CDROM).

DERPSCH R; CALEGARI A. 1992. Plantas para adubação verde de inverno. Londrina: Iapar. 80p. (Iapar Circular, 7).

ECHER MM; DALASTRA IM; DALASTRA GM; GUIMARÃES VF. 2010. Produtividade de quatro grupos de alface cultivadas em sistema convencional e plantio direto na palha, na região Oeste do Paraná. In: CONGRESSO BRASILEIRO DE OLERICULTURA, 28. Resumos... Guarapari: SOB (CD-ROM).

EMBRAPA, Centro Nacional de Pesquisa em Solos. 2006. Sistema brasileiro de classificação de solos. Rio de Janeiro: Embrapa-Solos. 306p.

EPAGRI, Empresa de Pesquisa agropecuária e Extensão Rural de Santa Catarina. 2004. Sistema de plantio direto de hortaliças: o cultivo do tomateiro no vale do Rio do Peixe. 2004. Florianópolis: 53p. (Epagri. Boletim Didático 57).

GIACOMINI SJ; AITA C; VENDRUSCOLO ERO; CUBILLA M; NICOLOSO RS; FRIES MR. 2003. Matéria seca, relação $\mathrm{C} / \mathrm{N}$ e acúmulo de nitrogênio, fósforo e potássio em misturas de plantas de cobertura de solo. Revista Brasileira de Ciência do Solo 27: 325-334.

INSTITUTO ADOLFO LUTZ. 2005. Métodos fisico-químicos para análise de alimentos. Brasília: Ministério da Saúde, ANVISA. São Paulo: Instituto Adolfo Lutz 1018p.

MAROUELLI WA; SILVA HR; MADEIRA NR. 2006. Uso da água e produção de tomateiro para processamento em sistema de plantio direto com palhada. Pesquisa Agropecuária Brasileira 41: 1399-1404.

MELO RAC; MADEIRA NR; PEIXOTO JR.
2010. Cultivo de brócolos de inflorescência única no verão em plantio direto. Horticultura Brasileira 28: 23-28.

NASCIMENTO JUNIOR A; SATTLER A; LORINI I; MACIEL JLN; DENARDIN JE; FERNANDES JMC; SALVADORI JR; VARGAS; PEREIRA PRVS; SPERA ST; WIETHOLTER S. 2005. Embrapa Trigo, Manejo e conservação do solo. Sistema de Produção, 2.

OLIVEIRA FL; RIBAS RGT; JUNQUEIRA RM; PADOVAN MP; GUERRA JGM; ALMEIDA DL; RIBEIRO RLD. 2003. Uso do pré-cultivo de Crotalaria juncea e de doses crescentes de "cama" de aviário na produção do repolho sob manejo orgânico. Agronomia, 37: 60-66.

OLIVEIRA NG. 2004. Plantio direto de alface e feijão-vagem sobre coberturas vivas perenes de Paspalum notatum e Arachis pintoi sob manejo orgânico. Seropédica: UFRRJ. 65p (Dissertação mestrado).

PEDROSA MW; MASCARENHAS MHT; FREIRE FM; VIANA MCM; GONÇALVEZ LD; LARA JFL; FERREIRA PC. 2012. Produção e qualidade da moranga híbrida em resposta a doses de nitrogênio. Horticultura Brasileira 30: 355-358.

RIBEIRO MAS; SKORANETO S; SANTOS JAB. 2001. Plantio direto na pequena propriedade. Informe Agropecuário 22: 100-108.

SAEG. 2007. SAEG: Sistema para Análises Estatísticas, versão 9.1. Viçosa: UFV.

SILVEIRA JC. 2007. Sistema de plantio direto de hortaliças (SP-DH): fundamentos e estratégias para um desenvolvimento rural sustentável. Florianópolis: UFSC. 38p.

SILVA VV. 2002. Efeito do pré-cultivo de adubos verdes na produção orgânica de brócolos (Brassica oleracea var. italica) em sistema de plantio direto. Seropédica: UFRRJ. 86p (Dissertação mestrado).

SODRÉ FILHO J; CARDOSO AN; CARMONA R; CARVALHO AM. 2004. Fitomassa e cobertura do solo de culturas de sucessão ao milho na Região do Cerrado. Pesquisa Agropecuária Brasileira 39: 327-334.

TRANI EP; PASSOS FA; TAVARES M; AZEVEDO FILHO JA. In: RAIJ VB; CANTARELLAH; QUAGGIO JA; FURLANI AMC. 1997. Recomendação de adubação e calagem para o Estado de São Paulo. Campinas: Instituto Agronômico/Fundação IAC. $147 \mathrm{p}$. 